\title{
Writing a research proposal: planning and communicating your research ideas effectively.
}

Juliet Eve

\section{Introduction}

This article is designed to guide you through the stages in writing an effective research proposal. It covers the when, why and how to aspects of research proposals, and uses examples to illustrate the most effective way to communicate research ideas. It is, in part, designed to support those seeking to submit a proposal for the LIRG Research award, and thus to complement the advice given on the LIRG website ${ }^{1}$, but it also serves as general guidance for anyone wishing to prepare a research proposal for a range of contexts.

\section{When and why to write a proposal}

Writing a research proposal is usually a response to some kind of external requirement to do so - most commonly in order to access some funding for your work, or as part of formal requirements when studying for a degree. In these instances, there will be particular requirements to be adhered to (word lengths, structure and layout of the application, a breakdown of costs etc.) and which you should pay close attention to. However, all research proposals adhere to a similar format, and you would expect to include the following:

- Title

- Introduction/Context of study

- Aims and Objectives

- Literature Review

- Research design/Methods

- Ethical considerations

1

http://www.cilip.org.uk/specialinterestgroups/bysubject/research/activities/awards/researchaward.h tm

\section{Juliet Eve}

Juliet Eve is a Principal Lecturer in the School of Computing, Mathematical and Information Sciences at the University of Brighton. She specialises in teaching research methods.

Email: j.eve@brighton.ac.uk 
- Indicative outputs

- Project timetable

- Statement of costs

In addition to the instances when more formal types of proposal are required, there are a number of other contexts when a proposal may be useful. Research requires resources - and even if you do not need financial support for your work, you may well need time in which to complete it. To access either of these, you will usually be required to persuade your manager or employer that the research is worthwhile, and having a research proposal to act as your 'calling card' in these circumstances is highly valuable. Remember that your proposal is a communication device: it is the means by which you will persuade someone to give you the support you need. It is therefore essential to articulate your ideas clearly and concisely, and to provide evidence that, in essence, you know what you are doing!

In addition, a proposal is not just an external communication - it is a valuable tool for you in a variety of ways, and is therefore worth doing even if you do not require funding. Firstly it helps you get your ideas in order, and to focus your research, so you can be clear as to the direction and purpose of your work. Secondly, it requires you to do some initial reading around the area, which can help to hone your thinking, provide a theoretical base for your work, uncover a piece of work that has done the research already (this may not be what you want to find, but it saves you either discovering it later on when the research in underway, or from 're-inventing the wheel'), and may give you ideas about what methodological approach to take. Thirdly, and importantly, it helps keep you on track as you undertake the work: having a proposal, with your aims and objectives clearly stated, prevents you from following white rabbits 'down some dark, forbidding tunnel' (Pickard, 2007, 56).

The article now addresses each of the aspects of a proposal set out above in turn.

\section{Title}

Your title should ideally be a sentence which clearly communicates your topic of research. Although it is perhaps tempting to spend time thinking up catchy or clever titles, this can be a distraction from the real work at hand! Go for something short and crisp, which provides a clear indication of the area of work; similarly when writing up your research, you want the title to provide information to potential readers, in order that they can judge its potential relevance to them quickly and easily. The following example, taken from the current issue of Library and Information Research is a good example of a clear title:

The effect of motivation on publication productivity of UK LIS academics.

Finalising your title may well be something you leave until you have completed your aims and objectives, and there should be a clear relationship between the two. Thus, a title from a recent Masters dissertation at Brighton reads: 
Web 2.0, Librarians, and the Information Explosion: attitudes and applications in an academic library.

This clearly relates to the aim of the study, which was:

To explore staff perceptions and expectations of Web 2.0 technologies within an academic library setting.

(Collingwood, 2008, 6)

\section{Introduction/Context of study}

This is where you provide the introduction to and context for your research, establishing why it is relevant, important, and/or timely. It is also where you address where the idea for the research began. Research often comes about through a personal interest in a topic, or in response to something you may have observed in your workplace or sector, or may even be something you have a 'hunch' about and want to follow up. All these are perfectly valid reasons for wanting to have the opportunity to investigate a topic in a more systematic way. However, it is equally important in this introductory section to draw on relevant existing literature (and this might be a mixture of policy documents, previous research, and theoretical work in your area of interest) in order to establish the rationale for work in your chosen area. Thus literature cited here, and the concepts and ideas briefly presented as context, will be elaborated upon in the literature review section of the proposal. It is useful to establish at this point, what contribution your research will make to existing knowledge in this area. This may seem like a daunting prospect, but remember that you do not have to be proposing a new theory or revolutionising the study of library and information management to make a contribution. As Pickard suggests:

knowledge grows incrementally with each new contribution, however small or localized that contribution might be.

(Pickard, 2007, 51)

\section{Aims and objectives:}

Aims and objectives are not easy to write; my experience teaching students over the last seven years has taught me - and them! - that translating good research ideas into clear aims and objectives can be a painful and time-consuming task. I start them with an exercise which requires them to imagine they are in the pub, explaining to friends in a sentence or two, what their research is about. If they can communicate that effectively, they have a basis from which to develop a more formal statement of aims and objectives.

If you are having difficulty arriving at an aim, consider your research in terms of a question (or set of questions). What exactly is it that you want to find out? This question can then be re-worked as your aim. Indeed, some research articles articulate both an aim, and specify what questions are being explored. The example aim given above about academic librarian's perceptions of Web 2.0 arose from a set of original questions the student wished to explore - and which were articulated as part of her aims and objectives, including the questions: 
- Do staff members think of Web 2.0 predominantly in terms of social networking applications such as Facebook?

- If so, does this affect their expectations [...] about what Web 2.0 can offer?

Ideally, your research aim should be stated in a sentence (or perhaps two). It should not, however, be a long paragraph containing explanatory detail. If you require several sentences of explanation to communicate the aim of your research, the chances are it is not focused enough. The aim should be a fairly general statement of what you wish to explore, such as this example from a piece of research I undertook in 2006:

The aim of the project is to investigate the role of research in the working practices of library and information professionals and archivists.

(Eve \& Schenk, 2006, 39)

Following on from - and related to - the aim should be a set of objectives (which can be listed in bullet point form); the ideal here is to provide focus, by narrowing down the general statement of the overall aim. This can be achieved by thinking through the exact issues you wish to address (which may relate to specifying a particular sector, a set of users, a certain timeframe etc.). The objectives give an idea of the types of areas you will address within the research. As a rough guide, between three and seven objectives is a sensible number. The objectives developed from the aim quoted above were as follows:

Specifically, the research will focus on:

- Identifying what, where, and how and why practitioners access research outputs (or do not).

- Understanding how practitioners implement research findings in their everyday practice, or what they need to expedite their ability to do so.

- Identifying the extent to which practitioners see themselves as active researchers, and as contributing to both the research agenda more widely as well as specific research projects.

- Understanding what access practitioners have to research methods and tools, how empowered they feel to use them, and what can be done to improve this.

- Evaluating the range of networks practitioners and academic researchers engage in, and how they contribute to successful dialogue and collaboration between the two groups.

Try not to get too specific - a common mistake is to go into the level of detail that is required at a later stage of the research, such as developing individual questions that might be used in interviews or questionnaires. You will need to consider the relationship between the aims and objectives - another common mistake is to concentrate on focusing the aim, and then inadvertently expanding the breadth of your research remit by trying to cover too much in the objectives.

An alternative to developing a set of aims and objectives is to establish a hypothesis - a proposition that you wish to test - as the basis for your research. 
This type of approach is most commonly associated with scientific research, and a research design involving experiments, which can test the validity, or otherwise, of your hypothesis. Starting from a hypothesis usually implies quantitative research on a large scale, and is not commonly associated with more investigatory enquiries.

\subsection{A worked example}

As with all research, it is difficult to teach someone how to do it in the abstract the best way to learn is to do. It may be useful at this point to work through an example.

Imagine you are interested in conducting some research into the e-books your library has been investing in. Robson $(2002,59-60)$ suggests that research questions are linked to purpose; thus a study may be explanatory (Do students have better access to high quality resources as a result of the investment in ebooks?); or exploratory, (What are students' experiences of accessing and using ebooks?) or descriptive (What are students' views about the provision of e-books in our institution?)

You also need to decide exactly what it is you wish to find out (this is important not only for deciding on aims and objectives, but also for choosing appropriate method(s)): is it a question of counting usage; is it how e-books are being used; do you want to focus on student use or staff use; is it perceptions of e-books; is it an evaluation of impact of e-books? Key here is to be very clear about the questions you need answers to, and, particularly if you are interested in conducting some kind of evaluation project, not to conflate usage, for example, with impact, or perceived value with actual value.

Thus, your aim might be articulated as:

To evaluate the use of e-books by students at the University of Brighton.

Your objectives would then need to focus on exactly which aspects of this you wished to explore, and to give an idea of which students, on which courses etc. For example, imagine your research was to answer the question: is the money spent on e-books for undergraduates well spent or a waste of resources? You would need then to develop objectives which allowed you to collect data to answer that question. Thus, one of your objectives might be:

- To identify uptake and usage of e-books by undergraduate students across a range of courses.

If you were also interested in why students used e-books (or didn't), and their perceptions about the value of them, your objectives would need to reflect that. Thus you would formulate additional objectives focusing on those aspects of the question:

- To identify the reasons for use or non-use of e-books amongst undergraduate students.

- To explore undergraduate perceptions about the value of e-books. 
A common pitfall is to allow your own (often subconscious) preconceptions to influence how you formulate aims and objectives. The following objective (or research question) is taken from a published piece of research, on perceptions of electronic library resources:

- What are the benefits of ELR to students and teachers?

This objective has the built-in assumption that there are benefits - research should be designed to discover if, for example, benefits exist or do not exist, not to prove something the researcher already holds to be true.

\section{The literature review}

This section should provide an overview of the existing literature in your chosen area; it thus provides context for your chosen topic, and indicates how your research relates to the theories, themes and issues in your field of study. Your aim here is to provide an overview, but also an evaluation of the literature; it requires more than description. You should present a themed discussion of the material, and, if applicable, identify any gaps in existing research (which provide further justification for your own work).

Hart's Doing a Literature Review: Releasing the Social Science Imagination (1998) is a useful resource; it takes you through the stages of a literature review, from collecting resources, to analysing readings, to writing up. It is worth quoting his comprehensive definition of a literature review here:

The selection of available documents (both published and unpublished) on the topic, which contain information, ideas, data and evidence written from a particular standpoint to fulfil certain aims or express certain views on the nature of the topic and how it is to be investigated, and the effective evaluation of these documents in relation to the research being proposed.

(Hart, 2000, 13).

Writing a literature review is a creative exercise; you will have read around the topic, and you now need to present your 'guided tour' of that reading to the people reading your proposal. It is therefore important to present the material in a structured way; this may involve mapping the history or development of an idea, or developments in your topic, and you will also need to provide an assessment of current themes, theories and, possibly, conflicts. At this stage, the literature review will be indicative, in that you will not have enough time and space at proposal stage for a thorough review. Whatever you complete at this stage, however, will be highly valuable - it should ideally form the basis for your completed literature review at the writing up stage after you have finished the research project. What you are trying to do here is to establish that you are aware of and understand the major issues in your chosen field. The literature review also provides you with guidance as to the methods you may adopt in your study; how have other researchers approached this topic? It may be, for example, that you wish to replicate a methodology already tried and tested, or you may feel that a certain methodological approach has dominated research in your field and you therefore wish to approach the subject differently. 


\section{Research design and methods}

Your research design and choice of methods should be dictated by your aims and objectives - never choose your method first, or merely go for the most convenient or apparently easy. Having said that, there will sometimes be constraints on what you can do, particularly if you are carrying out non-funded research in your own organisation. You need to think carefully about what approach you will adopt, and which methods you will use - and why. Will the methods selected be:

- the most appropriate way of collecting the data?

- feasible in terms of time and resources?

- possible?

This section should be informed by relevant readings about your chosen methods, and you should reference appropriate research methods literature. There are many good research methods textbooks covering social science-type approaches to research; some are listed in the further reading at the end of this article. You should indicate specifically how your methods relate to your aims and objectives, and why they are appropriate for achieving them. You need here to demonstrate an understanding of what your chosen methods involve, and to indicate what some of the limitations may be. All research designs involve making decisions about what method to adopt, what to include, what to leave out. This is inevitable, and as long as your chosen method is appropriate for what you want to achieve, you can't be 'wrong' in how you tackle the research. It is important however to be clear and honest about what you will do, how you will do it, and why. Be upfront about any limitations of your planned approach - all research has limitations, and if these are acknowledged, it makes it easier to judge the proposal.

\subsection{Research design}

Your overall research design relates to questions of methodology - is it appropriate to pursue a quantitative, qualitative or mixed approach? Debates about quantitative versus qualitative approaches to gathering and analysing data can become very detailed, and indeed it can be argued that these terms represent not an approach to data collection, but to the treatment of that data. For example, questionnaires are commonly thought of as being 'quantitative' but can, of course, contain many open ended questions which provide qualitative data. Similarly, interviews provide qualitative data, but this could be analysed quantitatively.

What is important here is that the methods used are those which enable you to collect the data which can answer your original questions. Broadly speaking, a quantitative approach (questionnaires, usage figures, web log analysis) allows you to count things - such as usage of services, number of visits, and so should be used if you want to find out, for example, what you users do, or how they behave. If, on the other hand, you wish to explore why your users do - or don't do something, or how they perceive your service, a qualitative approach (interviews, focus groups, observation, discourse analysis) will be more appropriate.

Much library research - and this will be true if you are embarking upon a small scale study in your own workplace - uses a case study approach, whereby one or more instances are explored in detail in order to understand a wider issue. There is 
a large literature on case studies, and you should make reference to this if you likely to adopt this approach. You will need a provide a rationale for your choice of case study, and, if you are investigating one instance, or one service for example, be clear about how it can be used to illuminate issues to the wider sector. Case studies can be criticised for not being generalisable to other cases, but they can be relatable, providing sufficient detail for someone working in a similar situation to relate the findings to their own experience.

\subsection{Methods}

Once you have decided upon your overall strategy, you will need to select specific methods for collecting data. This usually involves asking questions, most commonly of people, but also of systems, or texts. At the proposal stage, you need to communicate to your audience that you have selected appropriate methods, and provide an indication of how you will implement them. If you intend to use questionnaires, you will need to indicate if these will be paper-based or online, and how you intend to pilot and distribute them. If you will be using interviews, will they be structured or semi-structured? At the proposal stage, you do not need to come up with a completed questionnaire or interview schedule for example, but you should have some idea about the topics you will be covering.

\subsection{Sampling}

It is also important at this stage that you know not just how you will collect data, but who you will be collecting it from. Again, you will need to refer to research methods literature to inform how you construct an appropriate sample. In general, large scale enquiries using questionnaires require samples which can be representative of your target population, and there are a number of techniques for enabling this. Continuing the e-books example, if you want to be able to say something reliable about the use of e-books amongst undergraduates, you will need to have sampled across courses and levels in a way which provides a representative data set. If, on the other hand, you are pursuing an exploratory study investigating perceptions of the value of e-books, and so using an interview method, you may not be as interested in how representative your sample is of the whole student body. In this instance, a small number of cases, which may well have been self-selecting (for example, responding to an invitation to participate), might be sufficient to collect the data you need. Again, it is what is appropriate for what you want to achieve that is important here.

Remember however, that what claims you can make from your data will be very different in each case - avoid making generalisations on the basis of a small, unrepresentative sample.

\subsection{Data analysis}

It is also helpful in the methods section to provide an indication not just of how you will collect the data, but your approach to analysing it. With quantitative data, you might wish to indicate if you will be using a software package such as SPSS, for example, and to identify what types of statistical tests you will be doing on the data. For qualitative data it is equally important that you have some kind of framework for analysis, as this can be a complex task. 


\section{Ethical considerations}

Your proposal should provide an account of any ethical considerations that are pertinent for the project, and you should be aware of the need to act in an ethical manner in the various stages of a project (formulating the research questions; data collection (informed consent); confidentiality and/or anonymity when presenting results; storage/destruction of data at the end of the project). Certain formal proposals will have specific requirements in this area, and you may need to refer to the guidelines of an institution or outside organisation. Doing research in health related areas, for example, will often require you to comply with strict NHS requirements. Some areas of research, such as working with children or disadvantaged adults, also require a careful consideration of how the research can be conducted, and in these instances, the use of a 'gatekeeper' is advisable, as they can not only facilitate access to a group of people, but also vouch for you.

\section{Indicative outputs}

It is helpful to have an idea about what will emerge from your research, and who it will be useful to - what contribution do you hope to make to knowledge and understanding in this area? Proposals to support applications for funding often require details about intended outputs from the project, in the form of journal articles, conferences etc. - namely an indication of what you will produce, and how you will disseminate it. Even if you are not submitting this type of proposal, it is useful to consider how you will write up and publicise your work. Who will your audiences be, and what type of dissemination activity will be most suitable? If you are conducting research in your own organisation, the outputs may be in the form of policy recommendations, and the most appropriate way to presents that might be a short executive summary focusing on results and recommendations, or a presentation to a management team. Alternatively, your research may lead to the development of a product, or new web design. Communicating with a wider audience is also essential; a great deal of valuable library research gets lost because it is not written up and disseminated beyond the boundaries of the originating institution - write an article for LIR!

\section{Timescale and resources}

This section should indicate what your timescale will be for the project, and demonstrate an understanding of the stages of the research, and how much time you will need to complete them. Remember that some activities will run through most of the life of the project (e.g. reviewing the literature), and that there will be overlap between stages. If you are embarking on a fairly long-scale project, it is also helpful to include points at which key deliverables are due. You may wish to include a Gantt chart as part of this section, which is a visual indicator of the stages of the project and their timescales.

Do not underestimate the importance of this aspect of the proposal; it is vital to have an idea of the stages of a project as well as the time needed to complete them in order to manage your time effectively.

This section should also include what resources you may need - particular equipment for example, or access to certain archives. Any proposals for research 
funding require quite detailed breakdowns of costings in terms of staffing, travel and subsistence, equipment etc. It must be clear from your proposal what financial assistance you are requesting, and for what purposes, and these must be realistic; if it is to buy staff time, this must match with your estimated timescale and should be presented as costs per hour or day. Where there will be matching or additional funding (e.g. from a host institution), this contribution to the overall budget should be clearly indicated. Even if the proposal is not being written for funding purposes, it is useful to consider the financial implications of travelling, if that is a necessary part of the research, and to identify what resources might be needed (such as recording equipment, access to a computer or a photocopier, or a particular piece of software). If you are part of a larger organisation, it may be helpful to identify what resources you can access (both equipment and expertise) from outside your own department.

\section{Preparing joint bids}

Many of us now, of course, do not carry out research in isolation, and funding bodies often look favourably upon partnership bids ${ }^{2}$. There is much literature on the benefits and challenges of partnership working, and a whole other article to be written about the whys and hows of collaborative projects, so here I will just touch on a few things pertinent to the proposal stage. It should be very clear in the proposal who the lead partner will be; in some cases it may be that funding body rules only allow, for example, an academic institution to be an award holder, but others can be bought in for specialist reasons (e.g. consultants). Whatever the nature of the partnership (practitioners and academics, academics and community organisations etc.), each party should be clear about what they bring to the partnership in terms of experience and expertise, and this should also be clear from the proposal. How the partnership provides complementary skills, and how it will divide up the work involved must be established. Particularly where more than two partners are involved, a clear project management plan (covering meetings, how the project partners will communicate, how often etc.) is essential. In the costings section, again, it is important that the costs for each party are set out (including what they be offering as matched funding, which may take the form, not of actual cash, but of expertise or funding-in-kind). Once again, being able to effectively communicate how a partnership will work to an external audience means that you will have thought through all these issues yourself, and thus be clearer about your own strategy.

\section{Conclusion}

Writing a research proposal is an excellent start to any research project, as it provides a structured way for you to engage with the topic and begin reading around the area, and it forces you to approach the research in a systematic manner. It also helps you to discover exactly what it is you want to do - by having to communicate this clearly to another audience, it clarifies the scope of the work for

\footnotetext{
${ }^{2}$ For example, the LIRG Research Award actively encourages and looks favourably upon joint bids from library academics and practitioners.
} 
yourself. As such, it is an investment worth making, whatever type or size of project you are embarking upon.

\section{Bibliography and recommended further reading}

Brophy, P. (2006) Measuring library performance: principles and techniques. London: Facet Publishing.

Bryman, A. (2004) Social research methods. $2^{\text {nd }}$ Ed. Oxford: Oxford University Press.

Collingwood, R. (2008) Web 2.0, librarians, and the information explosion: attitudes and applications in an academic library. Masters dissertation, University of Brighton.

Denscombe, M. (2002) Ground rules for good research: a 10 point guide for social researchers. Maidenhead: Open University Press.

Denscombe, M. (2003) The good research guide for small scale social research projects. $2^{\text {nd }}$ ed. Maidenhead: Open University Press.

Eve, J. \& Schenk, N. (2006) Research and practice: findings from the Interactions project, Library and Information Research, 30(96) 36-46.

Hart, C. (1998) Doing a literature review: releasing the social science imagination. London: Sage.

Mackey, A. (2008) Embedding information literacy in the curriculum at the University of Sussex: an exploratory case study. Masters dissertation, University of Brighton.

Pickard, A.J. (2006) Research methods in information. London: Facet Publishing.

Robson, C. (2002) Real world research: a resource for social scientists and practitioner-researchers. 2nd Ed. Oxford: Blackwell.

\section{Acknowledgement}

Thanks to my MA students at the University of Brighton, who each year give me the opportunity to enthuse about research methods, and each year teach me something new. In particular, thanks to two of this year's recent graduates who gave me permission to draw from their dissertations in writing this article. 